\title{
Mineração
}

\section{Estudo da influência da microestrutura do clínquer sobre a moagem na fabricação de cimento: microscopia eletrônica de varredura}

\author{
Vládia Cristina Gonçalves Souza \\ Laboratório de Processamento Mineral - UFRGS \\ Av. Bento Gonçalves, 9500, Sala 224, Porto Alegre, RS, Brasil.E-mail: zuca@ct.ufrgs.br \\ Carlos Hoffmann Sampaio \\ Laboratório de Processamento Mineral - UFRGS \\ Av. Bento Gonçalves, 9500, Sala 224, Porto Alegre, RS, Brasil.E-mail: sampaio@ufrgs.br \\ Luis Marcelo Marques Tavares \\ Departamento de Engenharia Metalúrgica - UFRJ - Centro de Tecnologia, Bloco F, Sala 210 \\ Cidade Universitária, RJ, Brasil.E-mail: tavares@metalmat.ufrj.br
}

\section{Resumo}

Como continuação de um estudo anteriormente realizado com microscopio óptico (MO) e lupa, sobre amostras de clínquer coletadas em uma fábrica de cimento no sul do Brasil, foram realizadas análises em microscópio eletrônico de varredura (MEV). O objetivo foi buscar mais informações que pudessem ou não corroborar o resultado de alto grau de corrosão dos cristais, apontado pelos primeiros instrumentos, devido à presença de um alto conteúdo de metais.

As análises em MEV mostraram a existência de um padrão de microfissuras e de corrosão dos cristais, tanto de alita quanto de belita. O uso do EDS ou EDX (energy dispersive X-ray) ajudou a fortalecer a hipótese de uma situação de alto conteúdo de $\mathrm{Fe}_{2} \mathrm{O}_{3}$ e fase líquida e de metais, inclusive titânio.

Palavras-chave: Clínquer, Moagem, Cimento, MEV.

\section{Abstract}

As continuation of a study previously realized with optical microscope and magnifying glass, on samples of clinker collected from a factory at south of Brazil, it was realized analysis on electron microscopic. The objective was search more information that could or not corroborate the high degree of corrosion of the crystals result, pointing by first instruments, due the presence of a high content of metals.

The analysis on electron microscope have show the existence of a model of microcracks and of corrosion of the crystals, as much alite as belite. The use of the energy dispersive $X$-ray help to fortify the hypothesis of a situation with high content of $\mathrm{Fe}_{2} \mathrm{O}_{3}$, liquid phase and metals, included titanium.

Keywords: Clinker; Grinding; cement, Microscopy; Metallic particles

Artigo recebido em 28/01/2002 e aprovado em 13/07/2002. 


\section{Introdução}

Embora a microscopia óptica (MO) e a lupa, em alguns casos, possam ser ótimos instrumentos para análise de clínquer, mesmo quando não usada a técnica de reagentes ou de análise por imagem, tais instrumentos não fornecem toda a informação necessária para a observação e análise do grau de corrosão dos cristais presentes. O padrão microestrutural, ou seja, a rede de canais porosa pode ser mais bem visualizada tridimensionalmente e em maiores e melhores resoluções no MEV (microscópio eletrônico de varredura). Por esse motivo, não há dúvida de que, para se realizar um estudo completo de caracterização, faz-se necessário o uso deste último instrumento, em especial, se possível, do auxílio de outros ainda, tais como difração de raio x para verificação da presença das fases minerais e dos metais.

Com técnicas mais avançadas, tais como o MEV, poderia ser argumentado de forma mais consistente que há um aumento de belita (também corroída, em casos de grau elevado de corrosão) e de cal livre como decorrência da corrosão da alita. Além disso, as suposições sobre as causas da corrosão, entre as quais a presença de um alto conteúdo de metais, em especial de óxidos de alumínio e de ferro durante o processo de formação do clínquer, somente poderiam ser confirmadas, caso fossem encontrados cristais ou elementos metálicos, tais como ferro ou hematita, titânio e/ou alumínio nas amostras. Isto poderia ser feito por meio de EDS, desde que fossem tomados cuidados especiais, tais como escolher sempre os mesmos elementos, durante a sondagem. Posteriormente, poderiam ser feitas análises de difração de raios x sobre as mesmas amostras, como complemento da técnica de EDS.

Dessa forma, objetivando a continuação de um estudo anteriormente realizado com MO e lupa, sobre amostras de clínquer coletadas em uma fábrica de cimento no sul do Brasil, foram realizadas análises em MEV, de modo a corroborar ou não o resultado de alto grau de corrosão dos cristais, apontado pelos primeiros instrumentos devido à presença de um alto conteúdo de metais.

\section{Metodologia}

O procedimento de coleta de amostras foi o mesmo usado para análises de MO e lupa, inclusive foram usadas as mesmas lâminas para análises em MEV. Tal procedimento consistiu em realizar amostragens, em dias diversos, da alimentação nova do circuito de moagem de cimento da fábrica, com duração em torno de 5 horas. A cada 15 minutos era coletado cerca de $1 \mathrm{~kg}$ de material (clínquer) diretamente sobre a correia de alimentação do moinho. As amostras foram enviadas para classificação via peneiramento, devidamente identificadas pelo dia e intervalo granulométrico ao qual pertenciam e, em seguida, confeccionavam-se as lâminas segundo a técnica de Insley [3]. Após análises em MO, as lâminas foram encaminhadas para metalização e análises em MEV.

\section{Apresentação e discussão dos resultados}

A seguir, apresentam-se os espectros de EDS (Análise Química Elemen-

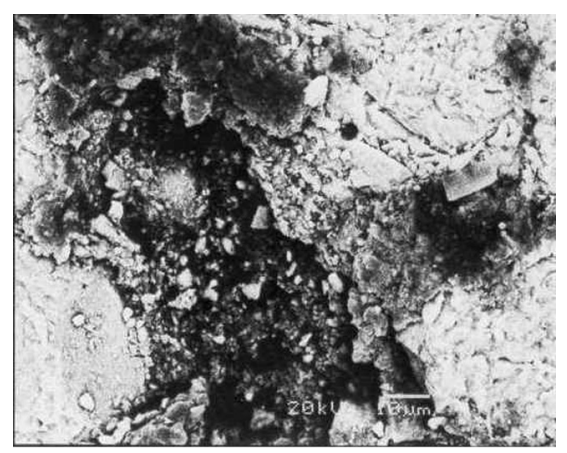

Figura 1 - Cristais de alita e belita no interior de um poro. BEl/ 20KV/ 950x.

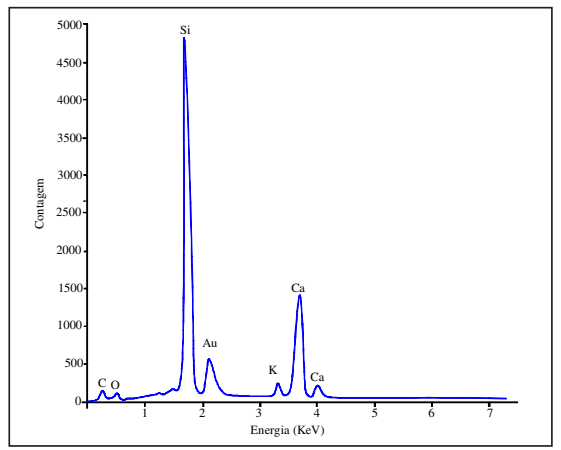

Figura 3 - Espectro de EDS realizado sobre cristais de belita da Figura 1. tar) obtidos a partir das lâminas examinadas em MEV, junto às fotos dos cristais. É preciso esclarecer que, em todos os espectros de EDS, a presença de ouro se deve à metalização das amostras.

Conforme se pode observar na Figura 1 , alguns cristais de belita à direita (aparecem em BEI mais escurecidos) mantêm sua forma preservada (prismática), no entanto a maioria dos cristais de belita encontram-se arredondados. Os cristais de alita que aparecem em tonalidade bem clara no interior do poro mostram corrosão nas bordas.

Na Figura 2, é apresentado um espectro de EDS, que foi realizado sobre uma área equivalente a toda a Figura 1. Por meio desse espectro, foi possível confirmar que os cristais são realmente silicatos cálcicos, alita e belita, ou seja, não são aluminosilicatos ou cristais ferroaluminosos da matriz.

As Figuras 3 e 4 apresentam os espectros realizados através de janelas que cobriam somente cada um desses minerais. Através desses, constatou-se que, quando focalizado um cristal de alita, a intensidade de cálcio era muito maior que

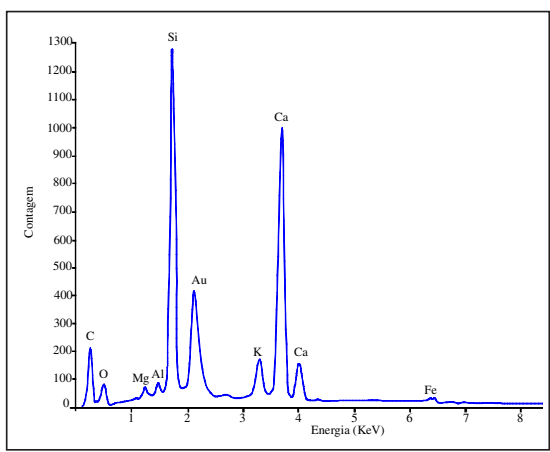

Figura 2 - Espectro de EDS realizado sobre cristais da Figura 1.

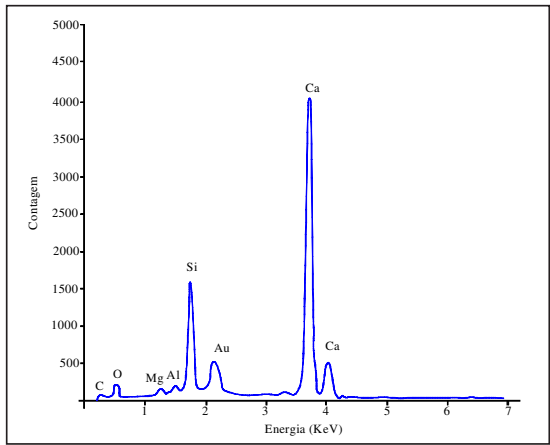

Figura 4 - Espectro de EDS realizado sobre cristais de alita da Figura1. 
a intensidade de silício e o contrário acontecia com os cristais de belita.

Esses espectros revelaram também a presença dos metais de magnésio, alumínio, ferro e potássio.

Na Figura 5, pode-se observar a enorme rede de canais em torno dos cristais de belita, constituída pelo alargamento dos poros durante processo corrosivo. No EDS realizado sobre a janela desta figura, registra-se uma grande intensidade de alumínio, além, é claro, de silício e cálcio. Isto é um indicativo de que existem cristais aluminosos da matriz nessa região, no caso, mais provável que seja a NE da janela aberta, na parte mais clara.

Na Figura 6, vê-se um cristal claro à direita na cauda em forma de meia-lua de um grão de alita. Esse cristal representaria o elemento de maior peso atômico, no caso poderia ser o ferro $(A=56)$ ou o titânio $(\mathrm{A}=50)$. $\mathrm{O}$ cristal escuro à esquerda representaria o elemento de menor peso atômico, no caso o silício $(\mathrm{A}=28)$.

De acordo com os espectros das Figuras 7 e 8, a não presença de alumínio e a pequena percentagem de cálcio são indicativos da existência, nesse local da lâmina, de cristais de óxidos de silício e de ferro em meio à massa vítrea (sílica amorfa). Os cristais de óxido de silício costumam aparecer com limites bem definidos, enquanto os cristais que apresentam nos espectros de EDS ferro e, inclusive, titânio costumam apresentar formas caracteristicamente anédricas ou mais arredondadas. Os espectros de EDS realizados sobre estes últimos (Figura 8) quase sempre apresentam ainda uma grande contagem em silício, pois é difícil isolar esses cristais da massa vítrea que os circunda. No entanto, os espectros realizados sobre os inicialmente supostos cristais de silício (Figura 7) sempre resultam em contagem de silício unicamente (embora esteja o programa "setado" sempre para procurar o mesmo conjunto de elementos). Isto vem a corroborar com a suposição de que, em plena massa vítrea, são formados cristais de silício (quartzo), passíveis de serem reconhecidos, não só pelo espectro EDS resultante, mas também por sua textura, forma diferenciada e por sua tonalidade cinza nitidamente mais escura do que os cristais de belita em BEI. Frisa-se que foram testados vários ângulos de rotação e inclinação para o mesmo local da amostra, provando-se que isto não tinha relação com o ângulo de incidência do feixe de elétrons, restando apenas a relação com o peso atômico do elemento.

Procurou-se identificar mais cristais de óxidos de ferro e de silício em outros pontos da lâmina e em outras lâminas contendo partículas de tamanhos diferentes. Nesta e em outras lâminas, foi possível identificar no interior dos grãos de alita uma percentagem considerável desses cristais e até mesmo a presença de óxidos de titânio por meio do EDS. Sabe-se que os cristais de óxidos de titânio $\left(\mathrm{TiO}_{2}\right)$, conhecidos como minerais de rutilo, apresentam freqüentemente impurezas como ferro entre outros tantos metais. Sabe-se, também, que o rutilo e outros metais alcalinos são reconhecidamente responsáveis pela chamada reação álcali-agregado, fenômeno altamen-

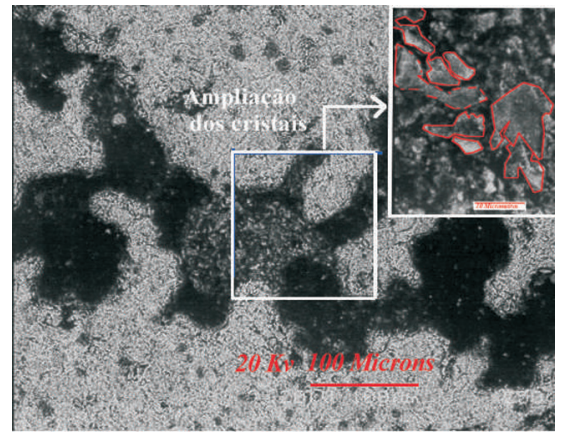

Figura 5 - Cristais de belita no interior de uma rede de canais. SEI/ 20KV/ 95x. Na ampliação, cristais de belita com bordas corroídas em BEI (20KV).

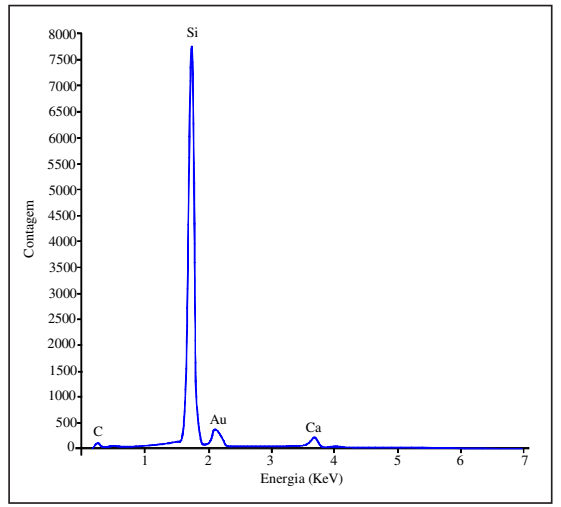

Figura 7 - Espectro de EDS realizado sobre cristal situado à esquerda da Figura 6 . te prejudicial à qualidade do concreto e de argamassas.

Odigure [1] investigou a influência dos óxidos de ferro sobre a moabilidade e a microestrutura do clínquer, através de misturas contendo co-produtos industriais (pastas abrasivas, contendo partículas metálicas), calcário e areia. Ele produziu várias amostras de clínquer em laboratório, analisou a composição química por microscopia óptica e difração de raios $\mathrm{x}$ e observou determinadas características, tais como porosidade e a microestrutura das mesmas no MEV.

Através das análises das fotografias no MEV, percebeu que o grande volume de espaços capilares (poros interconectados) era uma indicação de uma distribuição desigual da fase líquida. A natureza dentrítica dos poros e capilares mostrou que os cristais minerais de clínquer poderiam ser facilmente dissolvidos pela fase líquida corrosiva ou desintegrados em grãos menores.

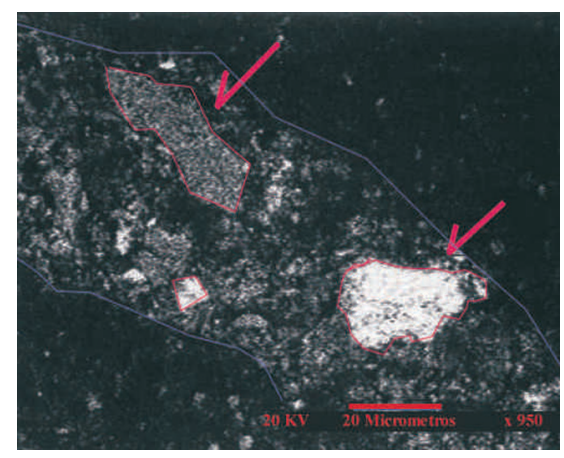

Figura 6 - Ampliação dos cristais inclusos na "cauda" de um grão de alita. BEl/20Kv/ 950x

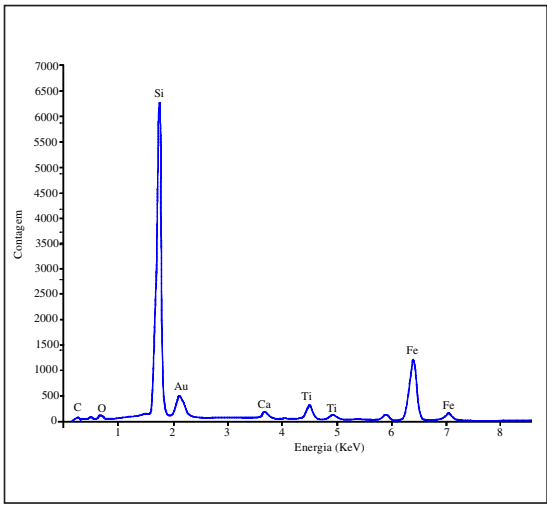

Figura 8 - Espectro de EDS realizado sobre cristal situado à direita da Figura 6 . 
Através da microscopia óptica, do MEV e das análises por difração de raios $\mathrm{x}$, Odigure [1] chegou à conclusão de que o valor de $\mathrm{C}_{3} \mathrm{~S}$ diminui com o aumento de $\mathrm{Fe}_{2} \mathrm{O}_{3}$, resultando na formação de mais $\mathrm{C}_{2} \mathrm{~S}$, o qual, em conjunto com os óxidos de alumínio e ferro, ajuda a baixar a moabilidade do clínquer e, ao mesmo tempo, a resistência mecânica do concreto (cimento de menor qualidade). Sabe-se, por exemplo, que o módulo de silicatos (MS), quando menor do que 2, de modo geral, está relacionado a uma sinterização mais fácil, porém a uma maior formação de fase líquida, baixa da qualidade, maior consumo de refratários, incrustação pouco estável e instabilidade do forno, ou seja, a uma menor economicidade do processo de sinterização. Isso está de acordo com as conclusões anteriormente citadas por esse autor.

Ele concluiu também que a presença de alto conteúdo de $\mathrm{Fe}_{2} \mathrm{O}_{3}$ e $\mathrm{FeO}$ (a alta percentagem de óxidos de ferro na fase líquida), devido ao uso de co-produtos industriais, afetaram enormemente a estabilidade da belita e levaram a desintegração da alita. Isto estaria, de acordo com seu estudo, igualmente relacionado com a observação de poros e microfissuras. As amostras contendo menor conteúdo de óxidos de ferro e mais alita não apresentaram (no MEV) padrões de formação ou crescimento de microfissuras. Naquelas amostras ricas em óxidos de ferro, desenvolveram-se redes capilares e microfissuras, as quais seriam responsáveis pela difusão de cátions para o interior das redes cristalinas dos minerais de clínquer. Esse fenômeno afetaria seriamente a morfologia e poderia ser o responsável pelo o que foi descrito pelo autor como "bancos de rios suaves", que se estendem por toda a superfície dos minerais de clínquer. Portanto a adição desse compostos no conteúdo adequado poderia contribuir enormemente para a moabilidade dos minerais.

Outro fato muito interessante assinalado naquele trabalho seria a enorme diferença entre o cálculo empírico de Bogue ou fórmula de Kind, usado para calcular as quantidades de cada mineral do cimento, em relação aos resultados apresentados por difração de raios $\mathrm{x}$.
Constatou-se, pois, o quanto esse cálculo pode ser enganador, apesar de ser ainda o mais usado na indústria cimenteira para controle da qualidade do cimento, inclusive na fábrica em que foi realizado esse trabalho.

Em espectros realizados sobre alguns cristais individualmente, identificados de forma clara em BEI, verificou-se a ausência total de cálcio (ou contagem desprezível, quando comparado com a presença de ferro ou silício, conforme as Figuras 7 e 8). Isso revelou a presença de uma grande percentagem de cristais de sílica livre (vidro); de óxidos de ferro e, inclusive, de titânio, elementos claramente não ligados à fase calcítica.

Por outro lado, espectros (ver Figura 10) realizados sobre cristais arredondados, com o aspecto análogo a uma "couve-flor", como os apresentados na Figura 9, demonstraram a presença quase única dos elementos cálcio e oxigênio, levando à conclusão de que estes eram os cristais de cal livre $(\mathrm{CaO})$.

Nas Figuras 11 e 12, pode-se ver os cristais de alita em detalhes, com suas formas parcialmente preservadas, porém com as bordas bastante corroídas.

Na Figura 13, encontram-se cristais de belita, no interior de um poro, com formato arredondado e muitas microfissuras. Tal descrição confere com o padrão de corrosão observado em microscópio óptico. Quando das observações dos poros em lupa, subsistia uma dúvida: se os cristais do seu interior estavam preservados ou não, uma vez que existia a probabilidade de que estivessem, à semelhança do que acontece no caso dos geodos, em que o resfriamento se dá de forma lenta. Com a análise em MEV, no entanto, ficou comprovado o fenômeno de corrosão.

Na verdade, portanto, o resfriamento lento não ajuda, no caso desses minerais, a formação de cristais maiores, nem a preservação de suas formas, porque o resfriamento lento facilita o processo de corrosão.

A alita sofre corrosão pela fase líquida presente, resultando em belita e cal livre. A belita, ainda bastante instá- vel, reage também com a fase líquida, resultando em seu arredondamento, microfissuramento e alargamento dos poros (formação da rede de poros interconectados). A cal livre ajuda a expandir ainda mais as microfalhas, podendo ocasionar a sua propagação e posterior desintegração dos grãos em grãos menores.

Um pequeníssimo orifício, situado no meio de um grão de alita, poderia estar preenchido por cristais de cal livre, os quais são muito pequenos para serem observados em MO nessa lâmina. Eis aí então um "defeito" não físico, não resultante de esforços mecânicos que a partícula tenha sofrido, mas trata-se de uma espécie de defeito "físico-químico".

Importante salientar, depois desses estudos, que foi tomado especial cuidado ao se analisar cada faixa do espectro, verificando-se todos os elementos possíveis de representarem cada pico e eliminando os que, de acordo com as inúmeras análises químicas da fábrica, nunca poderiam ali estar presentes. De fato, quase nenhum dos elementos presentes que aparecem nos espectros poderia ser confundido com outros vizinhos na Tabela Periódica, e a proporção entre os mesmos segue uma lógica bastante simples e convincente para ser rejeitada.

Portanto, através das relações entre elementos (p.e., \% em peso do elemento silício em relação ao cálcio) e, sobretudo, fazendo com que a cada novo EDS o programa de computador acoplado ao MEV procurasse somente os elementos reconhecidamente possíveis de estarem presentes no material, foi possível fazer a identificação das fases presentes no clínquer de cimento.

\section{Conclusões}

As análises qualitativas em conjunto com as análises quantitativas elementares revelaram fatos surpreendentes no que concerne a microestrutura do clínquer e sua relação com a porosidade, o que acabou por comprovar, mais uma vez, a importância desse tipo de análise na avaliação da qualidade do cimento e na eficiência do processo de moagem. 


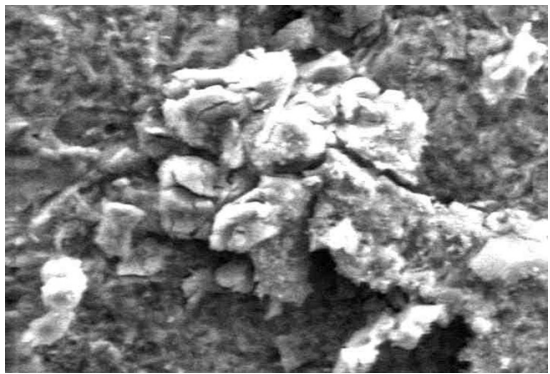

Figura 9 - Cristais de cal livre. SEl/ $20 \mathrm{KV} /$ $700 x$.

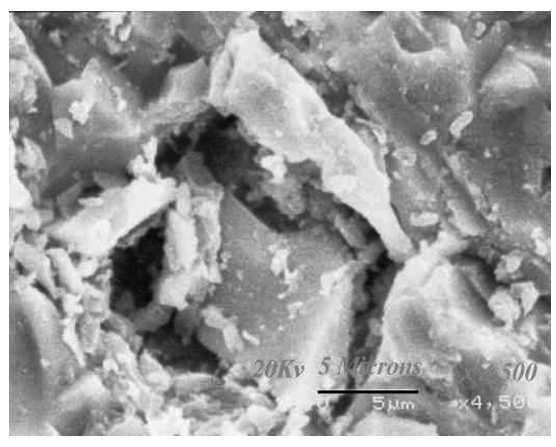

Figura 12 - Cristais de alita com bordas corroídas no interior de um poro.SEI/20KV/ 4500x.

Através das análises em MEV, verificou-se que existe um padrão de microsfissuras e de corrosão dos cristais, tanto de alita quanto de belita, o que só vem a corroborar com as análises realizadas em microscópio óptico e lupa. Fazendo uma analogia com os experimentos de Odigure [1] e por meio do EDS, é possível afirmar que existe uma situação de alto

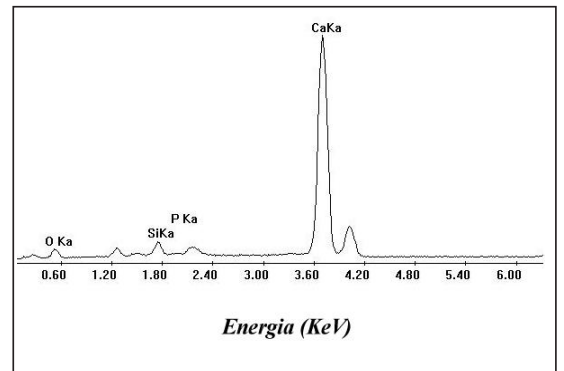

Figura 10 - Espectro de EDS realizado sobre cristais da Figura 9.

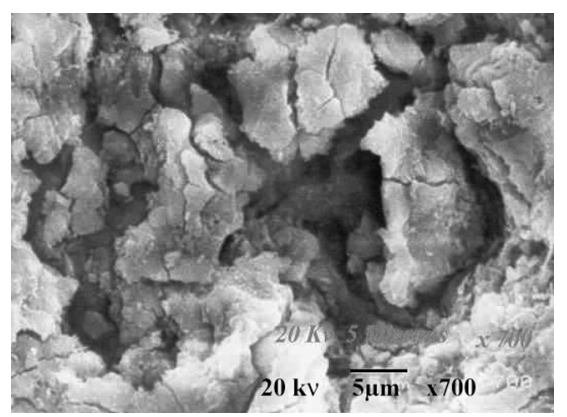

Figura 13 - Cristais de belita com bordas corroídas e microfissuramento. SEI /20KV/ $700 x$.

conteúdo de $\mathrm{Fe}_{2} \mathrm{O}_{3}$, e fase líquida, em especial $\mathrm{C}_{4} \mathrm{AF}$, bem como essa situação poderia estar sendo provocada pela presença de outros metais, tais como o titânio.

Nesse estudo, procuramos apresentar o papel dos metais, em especial do ferro, no fenômeno de corrosão da

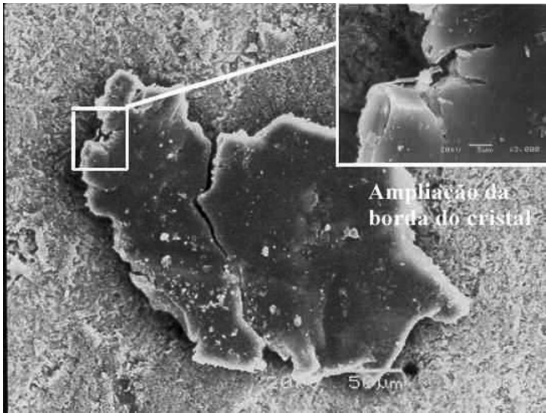

Figura 11 - Cristal de alita com bordas corroídas e microfissuramento. SEI/20KV/ 900x. Na ampliação, detalhe da borda do cristal corroído.SEl/ 20KV/ 3000x.

alita e perda da atividade de hidratação dos minerais de cimento. Dessa forma, seria altamente recomendável realizar análises de difração de raios $\mathrm{x}$, a fim de verificar a presença desses metais, assim como se faz necessário estimar as proporções em que os mesmos se apresentam.

\section{Referências \\ Bibliográficas}

[1] ODIGURE, J.O. Grindibility of cement clinker from raw mix containing metallic particles. Cement and Concrete Research, 29, p. 303-307, 1999.

[2] MONTEiRO, P. J. M., MEHTA, P. K. Concreto: estrutura, propriedades e materiais. São Paulo: Pini, 1994. p.161166.

[3] INSLEY, H.J., MCMURDIE, H. F. Res. Natl. Bur. standard, p. 20-173. 1938.

\section{Em janeiro de 2002 a REM completou 66 anos. Comemore conosco! Assine a REM}

